\title{
Differential Modulation of Word Recognition by Semantic and Spatial Orienting of Attention
}

\author{
Tamara C. Cristescu and Anna Christina Nobre
}

\begin{abstract}
In the present study, we investigated the ability to orient attention to abstract associative features of complex stimuli, more specifically, to the semantic categories of visual word stimuli. We compared the behavioral and electrophysiological effects of semantic orienting with those elicited by spatial orienting to word stimuli. Two parallel, cued lexical-decision tasks, with semanticor spatial-orienting cues, were used. Results showed that both semantic and spatial orienting facilitated behavioral performance. The event-related potential analysis revealed different and nonoverlapping patterns of modulation of word processing by semantic and spatial orienting. Modulation by semantic orienting
\end{abstract}

\section{INTRODUCTION}

The majority of event-related potential (ERP) studies of selective attention have investigated the modulatory mechanisms of spatial attention acting within the visual domain. In the case of spatial orienting (Posner, 1980; Posner, Snyder, \& Davidson, 1980), ERP studies with human participants have established that neural modulation leading to the behavioral enhancements can start at least as early as extrastriate visual processing, as reflected by commonly reported gain modulation of the P1 and/or N1 visual potentials (Hillyard \& AnlloVento, 1998; Hillyard, Vogel, \& Luck, 1998; Luck \& Ford, 1998; Mangun, Buonocore, Girelli, \& Jha, 1998; Mangun, Hillyard, \& Luck, 1993; Luck, Heinze, Mangun, \& Hillyard, 1990; Hillyard \& Mangun, 1987; Mangun \& Hillyard, 1987; Eason, 1981; Hillyard, Hink, Schwent, \& Picton, 1973; Eason, Harter, \& White, 1969). Similar mechanisms have been observed in studies investigating orienting to objects or object features. Studies investigating attentional orienting to objects have also shown gain modulation of the P1 and N1 potentials (Valdes-Sosa, Bobes, Rodriguez, \& Pinilla, 1998; Valdes-Sosa, Cobo, \& Pinilla, 1998). Studies investigating orienting to features have often shown that modulation based on spatial location precedes modulation based on feature values, which can additionally trigger selection-related negativities that are thought to reflect differential visual processing in feature-selective

University of Oxford started later, affecting only the potentials linked to conceptual or semantic processing (N300 and N400). The pattern of N300/ N400 modulation in the semantic-orienting condition was similar to that observed in semantic-priming tasks, and was compatible with the operation of controlled semantic processes. Spatial orienting significantly enhanced the amplitude of the early visual potential P1 as well as the language-related N400 potential. These findings showed that the similar end-result of behavioral facilitation by semantic and spatial orienting is achieved through largely distinct mechanisms acting upon separate levels of stimulus analysis. areas (Anllo-Vento, Luck, \& Hillyard, 1998; Anllo-Vento \& Hillyard, 1996). Together, the majority of research therefore suggests that a relative gating or gain-control mechanism operating at the perceptual level is a ubiquitous way through which top-down attention-related signals biases ongoing information processing (Hillyard \& Anllo-Vento, 1998; Hillyard et al., 1998; Hillyard \& Mangun, 1987).

However, more recent behavioral and electrophysiological evidence investigating attentional orienting outside the visual-perceptual domain has suggested the existence of a wider range of modulatory mechanisms. For example, attentional orienting to temporal intervals of visual events can bring about behavioral advantages through a different pattern of modulation compared to spatial orienting, and one that need not involve retinotopic enhancement of early visual potentials. Instead, in the absence of spatial certainty, temporal orienting exerts its effects mainly by modulating response-related stages of processing (Doherty, Rao, Mesulam, \& Nobre, 2005; Griffin, Miniussi, \& Nobre, 2002; Miniussi, Wilding, Coull, \& Nobre, 1999). These investigations therefore support the ability of attention to act outside the visual-perceptual domain, and through multiple types of mechanisms.

As a further test of the flexible and multiple nature of top-down modulatory attentional mechanisms, the present experiment was designed to investigate our ability to orient attention to postperceptual associative features of stimuli, which are also not related to response factors. Specifically, we investigated whether people can orient attention to semantic categories of words to 
improve behavioral performance. Early behavioral studies have suggested that it is possible to build expectations about the semantic category of a word in a voluntary and controlled way. When the semantic category of a word predicts the specific (and different) semantic category of a second word, recognition of the second word is improved (Neely, 1976; Posner \& Snyder, 1975a, 1975b). In addition, there is behavioral evidence that semantic associations between concrete stimuli can bias attention toward associated stimuli in a visual search task (Moores, Laiti, \& Chelazzi, 2003). To our knowledge, however, there are no studies to have investigated how orienting attention to a semantic category can modulate neural processing to optimize behavior.

We designed two parallel cued lexical-decision tasks, in which attention was oriented either to semantic categories or spatial locations of verbal stimuli (Figure 1A). The tasks were identical, except for the information carried by the cueing stimuli. The experiment used simple symbolic cueing stimuli to induce spatial expectations or expectations about semantic categories. The cueing stimuli were physically identical in the spatial and semantic conditions. The foveal symbols used as cues contained no intrinsic spatial or semantic information that could automatically affect detection of target words. This manipulation greatly reduced the possibility of automatic spatial or semantic priming effects between the cue and target stimulus.

Using very similar task designs in a functional magnetic resonance imaging study, we have recently shown that orienting attention to the semantic category of a word stimulus leads to a similar behavioral pattern of benefits and costs as orienting attention to its spatial location (Cristescu, Devlin, \& Nobre, 2006). Semantic and spatial cues, carrying predictions about semantic category and spatial location, respectively, both engaged activity in posterior parietal and frontal areas typically observed
Figure 1. The cueing stimulus $(\mathbf{x}$ or +$)$ was presented for $100 \mathrm{msec}$ following a fixation dot. Targets were presented after a variable fixation interval in the left of right VF. Targets were accompanied by a string of $x \mathrm{~s}$ in the opposite VF (A). Words were detected with higher accuracy in the valid-cueing condition in both experimental tasks (B). Words preceded by valid cues elicited shorter RTs than words preceded by invalid cues (C).

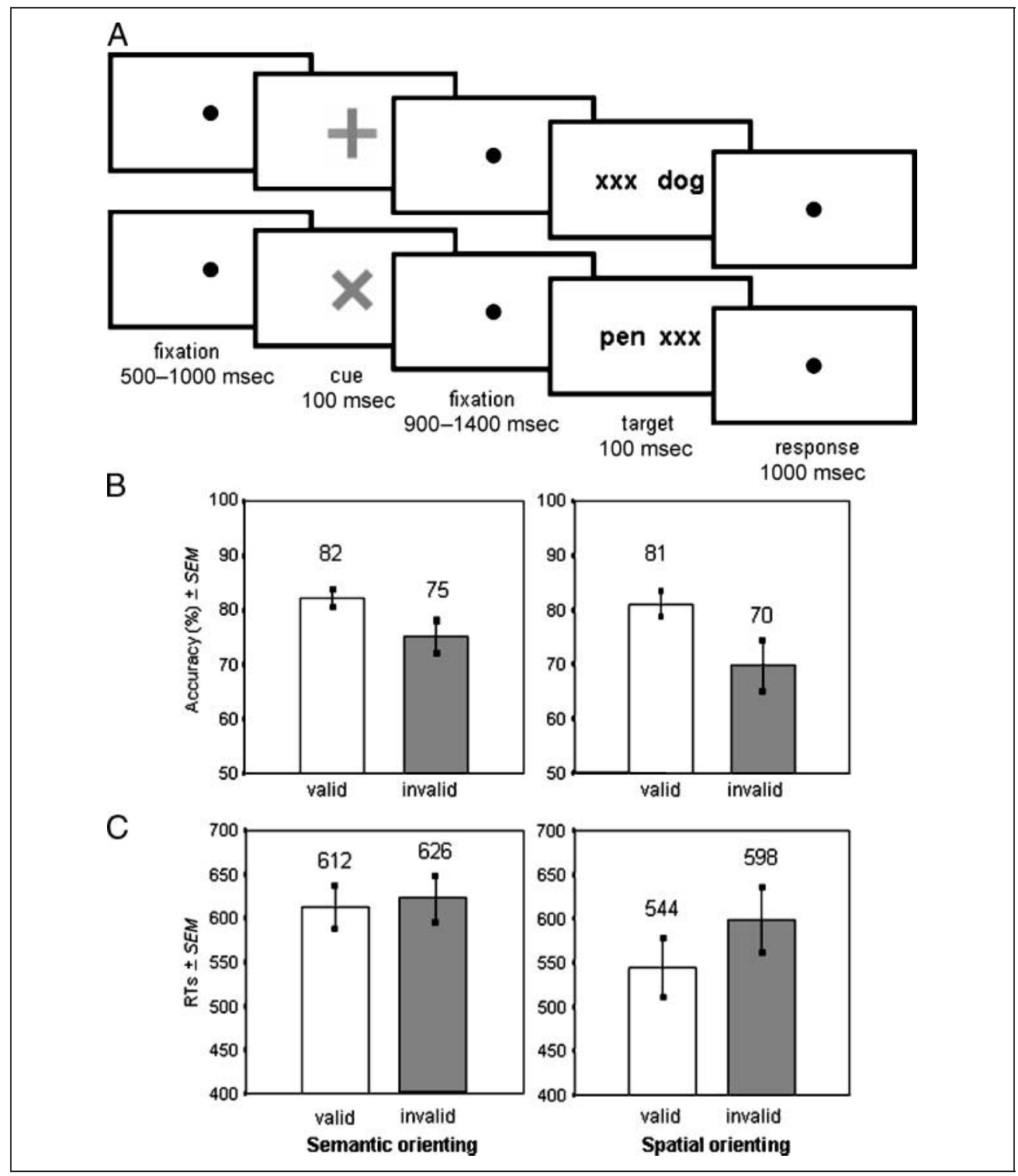


when attention is shifted between spatial locations or other perceptual attributes (Yantis \& Serences, 2003). In addition, semantic-orienting cues also activated brain areas linked to high-level semantic functions, such as the anterior inferior frontal gyrus, the angular gyrus, and the posterior temporal cortex, suggesting that these areas may play a role in generating the top-down attentional signals that can bias information processing (Bookheimer, 2002; Wagner, Pare-Blagoev, Clark, \& Poldrack, 2001; ThompsonSchill, D'Esposito, \& Kan, 1999). The temporal resolution of brain imaging methods based on hemodynamic measures, however, is insufficient to reveal how neural activity is modulated by the different types of attentional expectations in real time. We therefore turned to ERPs to compare and contrast the modulatory mechanisms.

We predicted that participants would build voluntary expectations about the semantic category of the upcoming word target and use these expectations to improve behavioral performance with the same type of end-result as when spatial expectations are used to optimize word recognition. However, we predicted that semantic and spatial orienting would modulate neural processing in different ways.

Neural modulation by spatial orienting to word stimuli has been investigated before. Therefore, we had clear predictions that spatial attention would increase the gain of visual potentials and of the later language-related N400 potential (McCarthy \& Nobre, 1993). This pattern of modulation has been interpreted to represent the top-down modulation of the perceptual analysis of words, which has cascading consequences for improving later analysis of word stimuli at the lexical or semantic stage. Because our task used bilateral stimulus arrays, we expected modulation of the P1 visual potential, but not of the N1 potential, in line with previous studies of spatial attention using bilateral arrays (Luck et al., 1990).

We expected that semantic orienting would not modulate visual potentials because there is no receptive-field attribute onto which top-down expectations about semantic categories could easily map. Instead, we expected semantic orienting to exert its effects directly upon semantic stages of word processing, and thus to modulate directly potentials reflecting conceptual or semantic analysis or integration, such as the N300 and N400 (Franklin, Dien, Neely, Huber, \& Waterson, 2007; Nobre \& McCarthy, 1994; Bentin, McCarthy, \& Hillyard, 1985; Kutas \& Hillyard, 1980). Such a finding would change the accepted view about attentional mechanisms by showing that top-down effects can influence information processing outside of the perceptual or motor stages of information processing.

\section{METHODS}

\section{Participants}

Data were collected from 52 participants (age range 20 to 26 years, 29 women), of which 28 were included in the final behavioral and ERP analyses. Participants were randomly assigned to one of two groups, each of which completed one attentional orienting condition (semantic or spatial). If a participant's data could not be used in the analyses (see below), another participant was tested in the same condition until each group contained 14 participants. All participants were strongly right-handed, with a mean score of +87.3 (standard deviation: 12.4) on the Edinburgh Handedness Inventory (Oldfield, 1971). Participants had normal or corrected-to-normal vision, and had no history of neurological disorders. All participants were native English-language speakers and monolingual. The study was conducted in accordance with the ethical guidelines of the Department of Experimental Psychology, University of Oxford, UK.

\section{Stimuli and Task}

Participants completed a cued lexical-decision task (Figure 1A). They viewed an informative cue followed by an array containing two peripheral letter strings at symmetrical locations in the two visual fields (VFs). One item was either a real English-language word or a pseudoword, and the other item was a string of $x$ s of the same length. Participants pressed a button if one of the items was a real English-language word, and refrained from responding if neither stimulus constituted a real word.

Each experimental trial started with a fixation dot presented on the center of the screen for a randomized interval of 500-1000 msec. Symbolic cueing stimuli were then presented centrally for $100 \mathrm{msec}$. The cue presentation was followed by a randomized interval between 900 and 1400 msec in which a fixation dot remained in the center of the screen. The target array then appeared briefly (100 msec), and was followed by a 1000-msec interval, during which participants had to respond by pressing a response button with the right index finger when a word stimulus was presented (67\% of trials) or refrain from responding when a pseudoword stimulus was presented (33\% of trials). An intertrial interval lasting 2000 msec provided a window for blinks and eye movements between trials.

The same simple symbols ( $\mathbf{x}$ and $\boldsymbol{+}$ ) were used as cueing stimuli in the two tasks. Each shape predicted a semantic category (animal or tool) or a spatial location (left VF or right VF) depending on the orienting task. Assignment of each shape to the specific semantic category or spatial location predicted was counterbalanced across participants. Cues correctly predicted the semantic category or spatial location of target words on $80 \%$ of trials (200 valid trials), and provided incorrect information on $20 \%$ of word trials ( 48 invalid trials). Pseudowords (124 trials) were presented on the left (64) or right VF (64 trials), and they were preceded by spatial (left/right) or semantic (animal/object) cues in equal proportion. Because semantic cues do not apply to pseudowords, 
we also made spatial cues preceding pseudowords nonpredictive. This ensured that the ability to derive a lexicaldecision response based on a matching process to the cued information (semantic category or spatial location) was equated for semantic and spatial cueing. Furthermore, because responses were only required and analyzed for word stimuli, any possible asymmetry in how the two types of predictive cues may have influenced pseudoword processing would not contribute to the resulting behavioral and ERP effects.

Target arrays were presented in lowercase letters using Arial font style (size 20), and were centered at $4.80^{\circ}$ horizontal eccentricity (maximum eccentricity was $5.15^{\circ}$ ). A word or pseudoword appeared in one VF, accompanied by a string of $x$ s containing the same number of letters presented symmetrically in the other VF.

The same stimuli were used in both orienting tasks. Two-thirds of the stimuli (248) were English-language nouns and one-third (124) were pseudowords. The nouns were three to eight letters long, belonging to the general category of "tools" or "animals," and were retrieved from the MRC Psycholinguistic Database (Coltheart, 1981). Tool nouns designated small, manipulable objects; and animal nouns designated mammals, insects, birds, and fish. Compound nouns and homonyms were excluded. It was not possible to equate all the psycholinguistic parameters between the two categories of nouns. Overall, tool nouns tended to be more familiar and less concrete than animal nouns (see Table 1). Consequently, in order to exclude the spurious contribution of any psycholinguistic effect to the results, two precautions were taken. Additional behavioral analyses were conducted on a "core" subset of word stimuli (90 animal and 90 tool nouns), which were carefully matched for frequency, familiarity, concreteness, and number of letters. The assignment of nouns to the valid and invalid cueing conditions was randomized among participants in each group.

Pseudowords were pronounceable, and were constructed by merging the initial letters of an animal noun with the final letters of a tool noun or vice-versa. The roots comprising the pseudowords were not recogniz-

Table 1. Psycholinguistic Parameters of Word Stimuli (Means and Standard Errors)

\begin{tabular}{lcccr}
\hline & $\begin{array}{c}\text { Animal } \\
\text { (Core) }\end{array}$ & $\begin{array}{c}\text { Tool } \\
\text { (Core) }\end{array}$ & $\begin{array}{c}\text { Animal } \\
(\text { All })\end{array}$ & \multicolumn{1}{c}{$\begin{array}{c}\text { Tool } \\
(\text { All })\end{array}$} \\
\hline Letters (3-8) & $5.1(0.2)$ & $5.3(0.2)$ & $5.3(0.1)$ & $5.2(0.1)$ \\
KF-Frequency & $7.4(1.1)$ & $8.3(0.9)$ & $7.9(1.2)$ & $10.3(1.2)$ \\
Familiarity & $476(7)$ & $491(7)$ & $478(7)^{*}$ & $497(6) *$ \\
Concreteness & $599(4)$ & $592(3)$ & $602(3)^{*}$ & $583(4)^{*}$ \\
\hline
\end{tabular}

These were equated for the "core" group of words, but values marked with an asterisk (*) differed across the entire word list used ( $t$ test, $p<.05)$. able, and the resulting chimeras did not resemble either tool or animal nouns (e.g., brab, dath, bugot, chista). Pseudowords were three to eight letters long (average 4.97, standard error 0.10), and matched the word stimuli for the number of letters.

\section{Procedure}

Experimental tasks were programmed and delivered with "Presentation" software (Neurobehavioral Systems, CA). Participants were seated comfortably in a dimly lit, electrically shielded room, and viewed stimuli presented on a screen placed $100 \mathrm{~cm}$ in front of them. Participants were asked to maintain fixation on the center of the monitor for the whole duration of the experimental trial, and to suppress saccades and blinks during stimulus presentation. The importance of giving fast and accurate responses following the target presentation was also emphasized.

\section{ERP Recording}

Electroencephalogram (EEG) data were recorded and analyzed using the Neuroscan 4.2 system. The EEG was recorded continuously from 34 scalp sites using nonpolarizable $\mathrm{Ag} / \mathrm{AgCl}$ electrodes mounted on an elastic cap (EasyCap) and positioned according to the 10-20 international system. Recording sites included 6 midline electrodes (Fz, FCz, Cz, CPz, Pz, Oz) and 14 electrodes over each hemisphere (FP1/2, F3/4, F7/8, FC3/4, FT7/8, C3/4, T7/8, CP3/4, TP7/8, P3/P4, P7/8, PO3/PO4, PO7/8, $\mathrm{O} 1 / 2)$. Additional electrodes were used as ground and reference sites. The midline AFZ electrode was used as the ground electrode. The EEG was referenced to the right mastoid and then re-referenced off-line to the algebraic average of the right and left mastoids. Electrooculogram (EOG) signals were measured bipolarly. Electrodes placed to the side of each eye measured the horizontal EOG (HEOG) and electrodes above and below the right eye measured the vertical EOG (VEOG). The signal was digitized at a sampling rate of $500 \mathrm{~Hz}$ and amplified 20,000 times. Data were recorded with a lowpass filter of $200 \mathrm{~Hz}$ using a DC setting.

Digital codes were sent from the stimulus-presentation computer to mark the onset of cue and target stimuli. The EEG was segmented off-line. Epochs started $200 \mathrm{msec}$ before the stimulus onset and ended $822 \mathrm{msec}$ after the stimulus onset. Event-related brain potentials were created for each group separately for validly and invalidly cued target word stimuli presented in the right $\mathrm{VF}$ and in the left $\mathrm{VF}$, as well as for cueing stimuli.

Epochs with eye-movement artifacts (blinks or saccades) were eliminated based on the EOG data. Blinks were identified as large wave deflections $( \pm 50 \mu \mathrm{V})$ in the VEOG, and were removed automatically by the software. 
Saccades were identified as square-wave deflections (of approximately $\pm 10 \mu \mathrm{V}$ ) in the HEOG electrodes and removed manually. Epochs containing large drifts or epochs where the voltage exceeded $\pm 150 \mu \mathrm{V}$ at any electrode site were also eliminated. To maintain an adequate signalto-noise ratio, a lower limit of 16 artifact-free trials per subject per condition was set. Individual ERP data that did not reach this threshold were excluded from the analysis.

Remaining individual data were checked for microsaccades and muscle artifacts using the independent component analysis algorithm of the EEGlab 4.311 software running on Matlab6 (Delorme \& Makeig, 2004). Independent components reflecting the above-mentioned artifacts were removed.

\section{Behavioral Analysis}

Behavioral analyses probed for modulations in performance accuracy and speed by semantic-orienting or spatial-orienting cues. Participants who performed at chance level on any valid cueing condition were excluded from further behavioral and ERP analyzes. Percent correct detection of words was used as the dependent variable in the accuracy analyses and median reaction time (RT) was used as the dependent variable in the RT analyses. Trials in which responses did not occur within 1000 msec after target presentation were regarded as errors and were excluded from the behavioral analyses (RT and accuracy).

Experimental effects on performance accuracy and RTs were assessed using mixed-effects analyses of variance (ANOVAs), which tested for the between-subject factor of task (semantic orienting, spatial orienting), and the within-subject factors of cue validity (valid, invalid) and VF of presentation (left, right VF). To rule out possible contributions from minor differences in psycholinguistic factors between nouns denoting animals and tools, two sets of analyses were carried out. In the main analyses, all words were included. In separate analyses, only the core list of words, equated for all psycholinguistic variables, was included. Only findings corroborated by the separate analyses on these "core" words were considered reliable.

\section{ERP Analysis}

The main aim of the experiment was to compare the effects of semantic versus spatial expectations on target processing. Separate ERP waveforms were constructed for validly and invalidly cued words presented in the left and right VF for the semantic and spatial task.

The ERP analysis focused only on words presented in the right $\mathrm{VF}$, and assessed the effects of task (semantic orienting, spatial orienting) and cue validity (valid, in- valid). Focusing on the right VF words was necessary in order to avoid conflating the effects of the well-known hemispheric dominance for lexical processing with the modulatory effects of attentional orienting, which were of central interest to the present experiment. Whereas words appearing in the right VF have direct access to critical language-related left-hemisphere brain areas, processing of words appearing in the left VF involves crossing the corpus callosum. Direct topographical comparison of ERPs elicited by target arrays containing words in the right versus left hemisphere confirmed the differential neural processing engaged as a consequence of hemispheric dominance. After the visual P1 and N1 time periods, neural processing of these arrays was associated with significantly different scalp distributions. Consequently, it would not have been possible to compare the modulatory effects of semantic orienting and spatial orienting upon similar stages of language-related processing for left and right words. Although the effects of hemispheric dominance upon words is an interesting topic in itself, it was tangential to the main experimental question addressed, and will not be discussed further.

Visual and language-related potentials of the ERP waveforms were analyzed using mixed-effects ANOVAs, which tested the between-groups factor of task (semantic orienting, spatial orienting) and the within-participants factors of cue validity (valid, invalid), electrode position, and electrode side. Follow-up subsidiary ANOVAs were used to assess the effects of semantic and spatial orienting in each group separately, where relevant. The GreenhouseGeisser epsilon correction factor was applied to account for possible effects of nonsphericity (Jennings \& Wood, 1976). Only corrected probability values and degrees of freedom are reported.

ERP analyses tested for attention-related modulation of early visual potentials and of later language-related potentials. The mean amplitudes of identifiable visual P1 and N1 potentials were assessed over symmetrical posterior sites where they were largest (O1/O2, PO3/PO4, and PO7/ PO8). The P1 potential was measured between 100 and $140 \mathrm{msec}$, and the N1 potential was measured between 150 and 190 msec. Modulation of the mean amplitudes of later potentials related to conceptual or semantic analysis or integration, N300 and N400, was tested over 15 electrodes, which sampled frontal-to-parietal regions of the scalp (F3/Fz/F4, FC3/FCz/FC4, C3/Cz/C4, CP3/CPz/CP4, and $\mathrm{P} 3 / \mathrm{Pz} / \mathrm{P} 4)$. The $\mathrm{N} 300$ potential was measured between 260 and $320 \mathrm{msec}$ and the N400 potential was measured between 350 and 550 msec.

In order to check for any other modulatory differences which may have been missed by traditional ANOVA-based analyses, an exploratory analysis was conducted using statistical cluster plots (Molholm et al., 2002; Murray et al., 2002). Cue-validity effects were compared separately for each task (semantic and spatial orienting) at each electrode site using pairwise $t$ tests. Additionally, effects of 
valid cueing were compared between semantic and spatial tasks at each electrode site using independent-samples $t$ tests.

In order to determine whether the differential modulations during the N400 time period involved the same or different sets of underlying neural generators, the topographies of the validity effects in the semanticorienting and in the spatial-orienting conditions were compared. The validity effects were isolated by subtracting waveforms elicited by invalidly cued targets from waveforms elicited by validly cued targets. The subtraction waveforms for the semantic-orienting and spatialorienting tasks were summarized by a limited number of scalp potential fields referred to as "segmentation maps" (Ortigue et al., 2004) using Cartool 3.2 software (Functional Brain Mapping Laboratory, Geneva, Switzerland). These segmentation maps represent periods of stable electrical field patterns and reflect dissociable functional states of the brain, which differ in their distribution of active neural generators and/or the weighting of their activity (Pascual-Marqui, Michel, \& Lehmann, 1995; Michel, Henggeler, \& Lehmann, 1992; Lehman, 1987). By comparing the maps and their duration across experimental conditions, it is possible to determine whether functional states differ in nature or in time course between conditions (Khateb et al., 1999).

In order to compare topographies independently of the amplitude of the ERP potentials, the subtraction ERPs were first re-referenced to the average reference and normalized by their global field power (Lehman, 1987). The global field power-normalized group data were then included in a segmentation process that is similar to a spatial-temporal cluster analysis. The segmentation process was performed between 0 and $800 \mathrm{msec}$ after stimulus onset, with the constraint that each scalp topography be observed for at least three consecutive data points (more than $6 \mathrm{msec}$ at a 500-Hz digitization rate) in the group-averaged data. The optimal number of maps that best explained the whole data was defined by a crossvalidation criterion (Pascual-Marqui et al., 1995). The segmentation analysis yielded a sequence of nonoverlapping scalp topographies for each condition. For the relevant time window (350-550 msec), the segmentation maps derived from the grand-averaged ERPs were compared by strength-independent spatial correlation with the moment-by-moment scalp topographies of the individual ERPs resulting from the initial subtraction. The scalp topography data for individual participants in each condition and for each time point were compared with the different segmentation maps and subsequently labeled according to the map with which they were most closely correlated. This comparison allows the verification of the presence of particular maps for each condition in each participant's data, and serves to determine the total amount of time a given topography was observed for an experimental condition across participants (Brandeis, Naylor, Halliday, Callaway, \& Yano, 1992).

\section{RESULTS}

\section{Behavioral Results}

Following preprocessing, data from 24 participants were discarded. The final behavioral and ERP analysis contained data from the same 14 participants in each group, performing either the spatial-orienting or semantic-orienting task (from a total of 23 initially tested in the spatialorienting task and 29 in the semantic-orienting task). The main reason for excluding a large proportion of the participants tested was the difficulty of performing the cued lexical-decision task on peripherally presented words in the absence of eye movements. The loss of a large number of trials, and consequently, of acceptable data quality for participants, is a common feature of tasks using peripherally presented words (see McCarthy \& Nobre, 1993). Data from 16 participants were rejected because of excessive artifacts related to eye movements or blinks, which led to an insufficient number of trials per cueing conditions. Eight further participants were excluded because they had low accuracy in the behavioral task. Although they were able to maintain adequate fixation, they found it difficult to perceive the letter strings using peripheral vision. The remaining 28 participants performed above chance level. They showed moderately high accuracy in detecting word targets in the semanticorienting task (82\%) and in the spatial-orienting task (81\%). Participants were also accurate in detecting and withholding responses to pseudowords in the semanticorienting task (78\%) and in the spatial-orienting task (76\%). Performance was not at ceiling.

\section{Accuracy Analyses}

The percentage of correctly detected word stimuli was used as a measure of performance accuracy in the lexical-decision task. The mixed-effects ANOVA showed a significant main effect of cue validity $[F(1,26)=15.68$, $p=.001]$. Participants were significantly more accurate to detect validly cued words (82\%) than invalidly cued words (73\%) (Figure 1B). There was no effect of task $[F(1$, 26) $=0.71, p=.408]$, showing that difficulty was well balanced between the semantic-orienting and spatialorienting tasks. There was also no interaction between cue validity and task, suggesting similar validity effects in each group $[F(1,26)=0.94, p=.342]$. The analysis revealed a main effect of VF of presentation $[F(1,26)=$ $33.91, p<.001]$. Word targets appearing in the right $\mathrm{VF}$ were detected with higher accuracy (83\%) than left VF targets (71\%). There were no other significant main effects or interactions.

A separate analysis using only the core set of words yielded qualitatively similar effects. The analysis confirmed the main effects of cue validity $[F(1,26)=$ $12.23, p=.002]$ and VF $[F(1,26)=33.55, p<.001]$, in the absence of a main effect of task $[F(1,26)=0.13$, $p=.721]$. 


\section{RT Analyses}

Median RTs were used to compare response speeds across experimental conditions. The mixed-effects ANOVA showed a main effect of cue validity $[F(1,26)=35.50$, $p<.001]$. Participants were significantly faster to detect validly cued targets ( $578 \mathrm{msec}$ ) than invalidly cued targets (612 msec) (Figure 1C). There was no significant effect of task between the groups, indicating that difficulty was well balanced between the two orienting conditions $[F(1,26)=1.25, p=.273]$. The interaction between task and cue validity was significant $[F(1,26)=12.76, p=$ .001]. Subsidiary ANOVAs showed that the validity effects were significant in both cases [semantic-orienting group: $F(1,13)=4.71, p=.049$ (validly cued target $=612 \mathrm{msec}$ and invalidly cued targets $=626 \mathrm{msec}$ ); spatial-orienting group: $F(1,13)=32.51, p<.001$ (validly cued target $=$ $544 \mathrm{msec}$ and invalidly cued targets $=598 \mathrm{msec}$ )]. However, direct comparison of the validity effects using an independent-samples $t$ test showed that the magnitude of the orienting effect was bigger in the spatial-orienting task $(M=54.3, S E=9.53)$ than in the semantic-orienting task $(M=13.6, S E=6.26)[t(26)=3.57, p=.001]$. The RT analysis also revealed a main effect of VF of presentation $[F(1,13)=16.14, p<.001]$ (left VF $=609 \mathrm{msec}$ and right $\mathrm{VF}=581 \mathrm{msec}$ ). There were no other significant main effects or interactions.

The analysis using only the core set of words yielded similar results, except that the interaction between task and cue validity was only marginally significant $[F(1,16)=$ $3.29, p=.081]$, showing more similar validity effects in the semantic-orienting and spatial-orienting conditions.

\section{ERP Results}

ERPs elicited by targets showed characteristic waveform topology, including early posterior visual potentials P1 and N1, and later potentials related to conceptual or semantic analysis or integration-N300 and N400.

\section{Visual Potentials}

Analysis of P1 mean amplitude showed no main effect of task (semantic orienting, spatial orienting), suggesting that its overall amplitude was similar in both groups $[F(1,26)=0.03, p=.874]$. The P1 analysis, however, revealed a significant effect of cue validity $[F(1,26)=$ $5.30, p=.030]$, which interacted with task $[F(1,26)=$ 5.24, $p=.030]$. Follow-up subsidiary ANOVAs showed that modulation of $\mathrm{P} 1$ amplitude was restricted to the spatial-orienting group. The amplitude of P1 was significantly larger for validly cued targets compared to invalidly cued targets in the spatial-orienting group $[F(1,13)=$ $12.33, p=.004]$, but there was no significant effect of cue validity in the semantic-orienting group $[F(1,13)<.001$, $p=$.993] (Figure 2). There were no other significant main effects or interactions during the P1 time window.
The N1 potential did not show any significant amplitude modulation by cue type or cue validity.

\section{"Semantic" Potentials}

Analysis of the mean amplitude of the N300 revealed a marginal effect of task $[F(1,26)=3.96, p=.057]$. The N300 tended to be larger (i.e., less positive in the case of

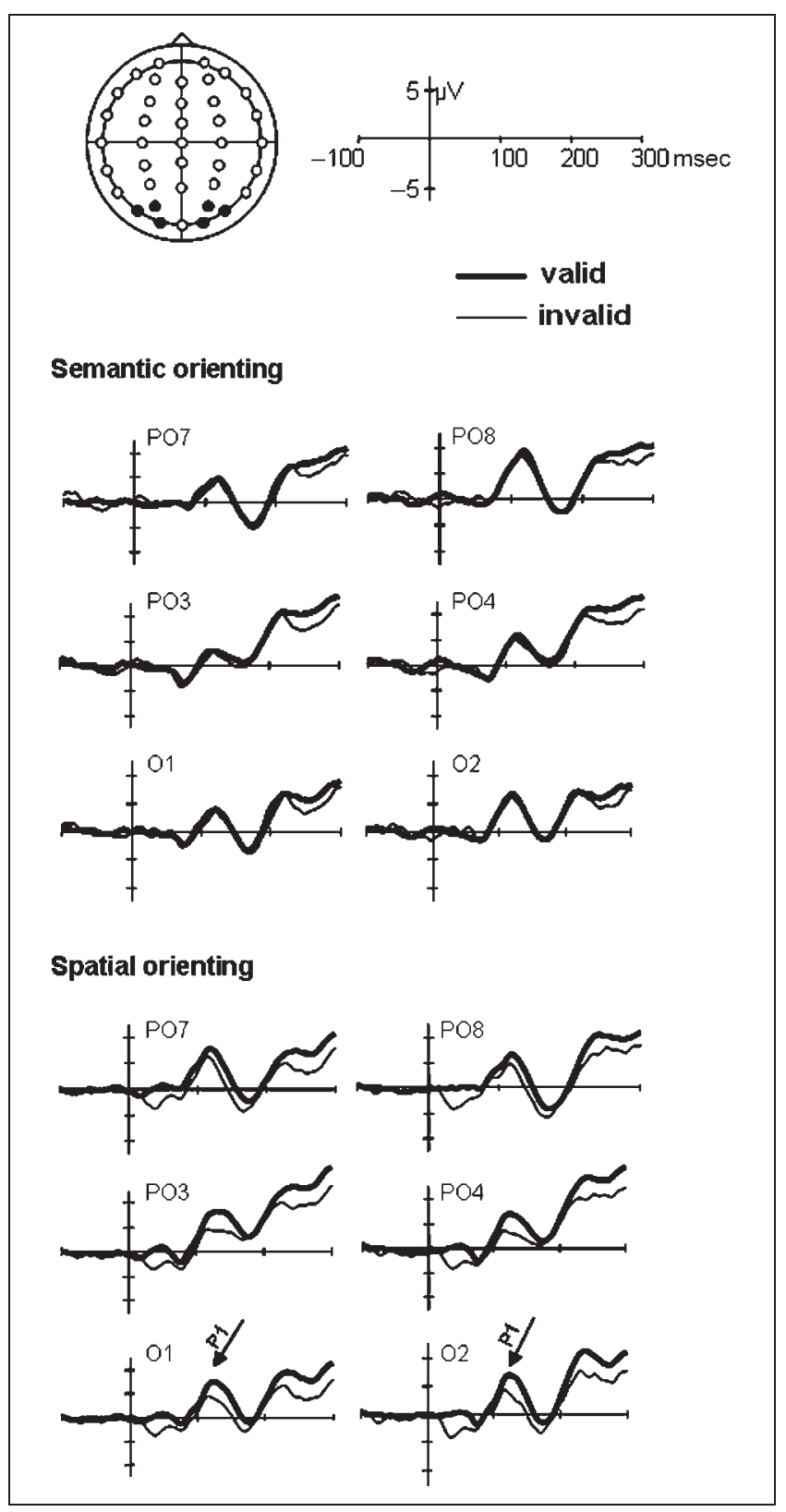

Figure 2. Early portion of grand-averaged waveforms over lateral posterior electrodes in the semantic-orienting condition and in the spatial-orienting condition elicited by right VF words following valid cues (thick line) or invalid cues (thin lines). Labeled arrows indicate the presence of statistically significant differences in P1 amplitude in spatial orienting task. Locations of analyzed electrode sites are shaded black on the electrode montage. The polarity of waveforms is plotted with positive values upward. 
this negative-going deflection) in the semantic-orienting task $(2.04 \mu \mathrm{V}$ mean amplitude) compared to the spatialorienting task ( $4.25 \mu \mathrm{V}$ mean amplitude) (Figure 3$)$. There was also a significant effect of cue validity $[F(1,26)=4.34$, $p=.047]$, as invalidly cued targets elicited larger N300 potentials (2.73 $\mu \mathrm{V}$ mean amplitude) than validly cued targets $(3.56 \mu \mathrm{V}$ mean amplitude). There were no other effects of interactions involving task or cue validity.

The N400 mean amplitude analysis revealed a main effect of task $[F(1,26)=5.66, p=.025]$. The N400 was significantly larger (i.e., less positive) in the semanticorienting task $(2.14 \mu \mathrm{V}$ mean amplitude) compared to the spatial-orienting task (5.02 $\mu \mathrm{V}$ mean amplitude) (Figure 3). The analysis also showed a significant interaction between task and cue validity $[F(1,26)=13.69$, $p=.001]$, demonstrating different patterns of $\mathrm{N} 400$ modulation in the two experimental conditions. Task and cue validity further interacted with electrode site task $[F(4,104)=6.38, p=.009)]$, suggesting that the validity effects were differentially distributed across the electrode sites in the two orienting conditions.

A subsidiary ANOVA in the semantic-orienting group showed that invalidly cued targets elicited a more negative $\mathrm{N} 400$ (1.21 $\mu \mathrm{V}$ mean amplitude) than validly cued targets $(3.07 \mu \mathrm{V}$ mean amplitude) $[F(1,13)=7.59, p=$ .016] (Figure 4). There was no interaction between cue validity and electrode site or side, showing that the cuevalidity effects were similarly distributed over the frontal to parietal electrodes sites $[F(4,52)<0.50, p>.50)]$.

A subsidiary ANOVA in the spatial-orienting group also showed a main effect of cue validity $[F(1,13)=6.10$, $p=.028)$, but the N400 pattern of modulation was different than that observed in the semantic-orienting condition. Targets preceded by valid spatial cues $(4.29 \mu \mathrm{V}$ mean amplitude) elicited a more negative N400 than targets preceded by invalid spatial cues $(5.74 \mu \mathrm{V}$ mean amplitude) (Figure 4). The cue validity effect in the spatial orienting group interacted with electrode site $[F(4$, $52)=8.32, p=.007)]$. Further subsidiary ANOVAs in the spatial-orienting condition demonstrated significant validity effects over the frontal and central electrode sites $[\mathrm{F} 3 / \mathrm{Fz} / \mathrm{F} 4: F(1,13)=14.15, p=.002 ; \mathrm{FC} 3 / \mathrm{FCz} / \mathrm{FC} 4: F(1$, $13)=14.32, p=.002 ; \mathrm{C} 3 / \mathrm{Cz} / \mathrm{C} 4: F(1,13)=5.99, p=$ $.029]$, but not over the posterior central and parietal electrode sites $[\mathrm{CP} 3 / \mathrm{CPz} / \mathrm{CP} 4: F(1,13)=2.02, p=.179$; $\mathrm{P} 3 / \mathrm{Pz} / \mathrm{P} 4: F(1,13)=0.19, p=.673]$.

Figure 5 shows the results of the topographical analysis of the subtraction waveforms isolating the validity effects
Figure 3. Grand-averaged waveforms elicited by right VF words following valid cues in the semantic-orienting condition (thick line) and in the spatial-orienting condition (thin line). Labeled arrows indicate the presence of statistically significant differences in N300 (260-320 msec) and N400 (350-550 msec) amplitude. Targets preceded by valid semantic cues elicited more negative waveforms within the N300 and N400 interval over the central-midline scalp sites. Locations of analyzed electrode sites are shaded black on the electrode montage. The polarity of waveforms is plotted with positive values upward.

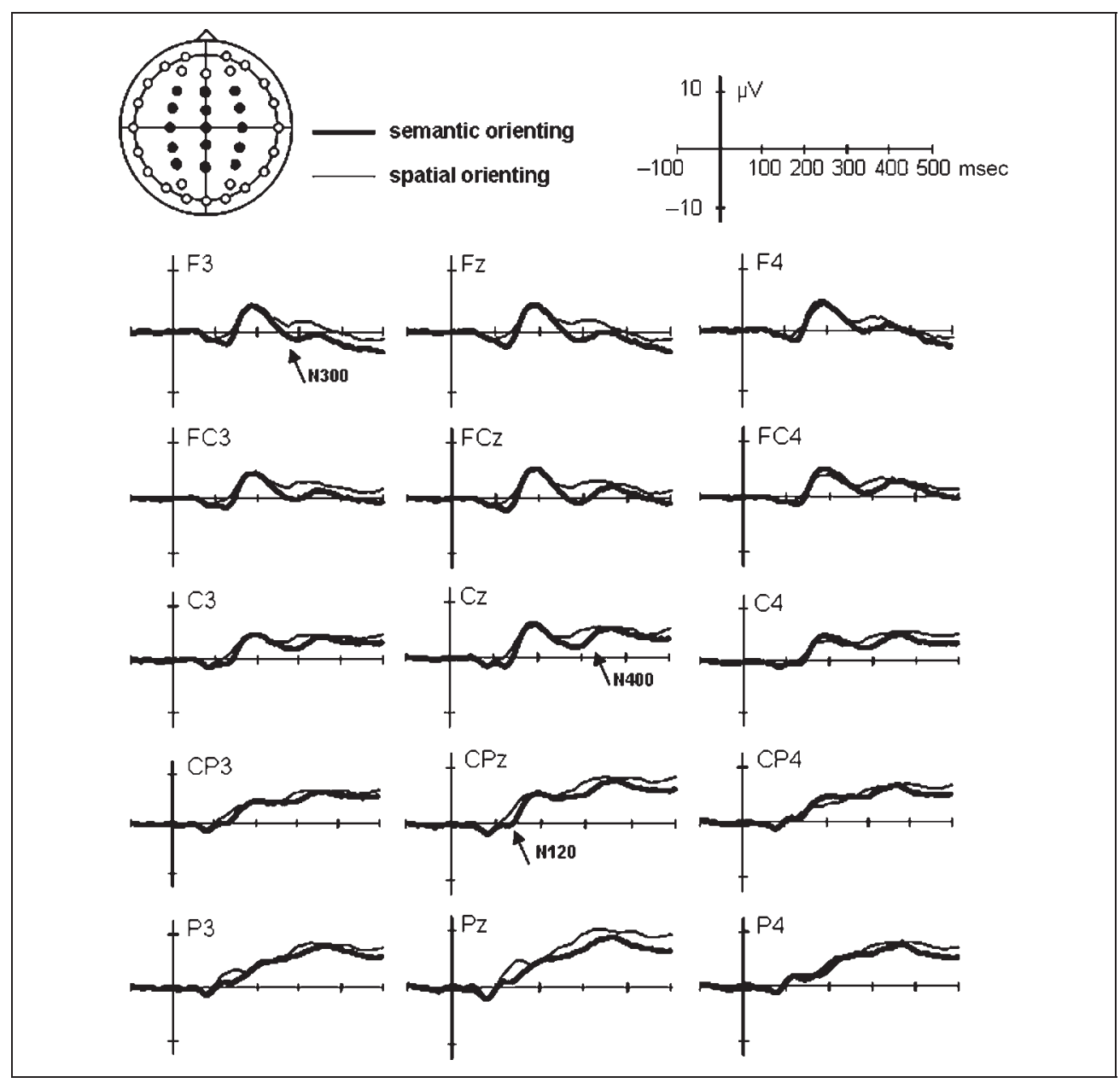


Figure 4. Grand-averaged waveforms are plotted separately for the semanticand spatial-orienting condition elicited by right VF words preceded by valid cues (thick lines) or invalid cues (thin lines). Labeled arrows indicate the presence of statistically significant differences in N400 amplitude (350-550 msec) for each attention-orienting condition. Locations of analyzed electrode sites are shaded black on the electrode montage. The polarity of waveforms is plotted with positive values upward.

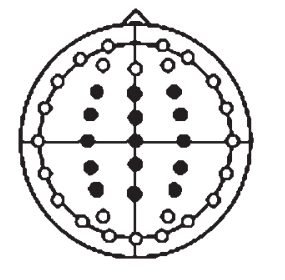

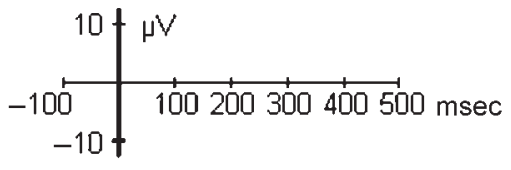

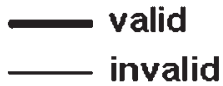

Semantic orienting invalid
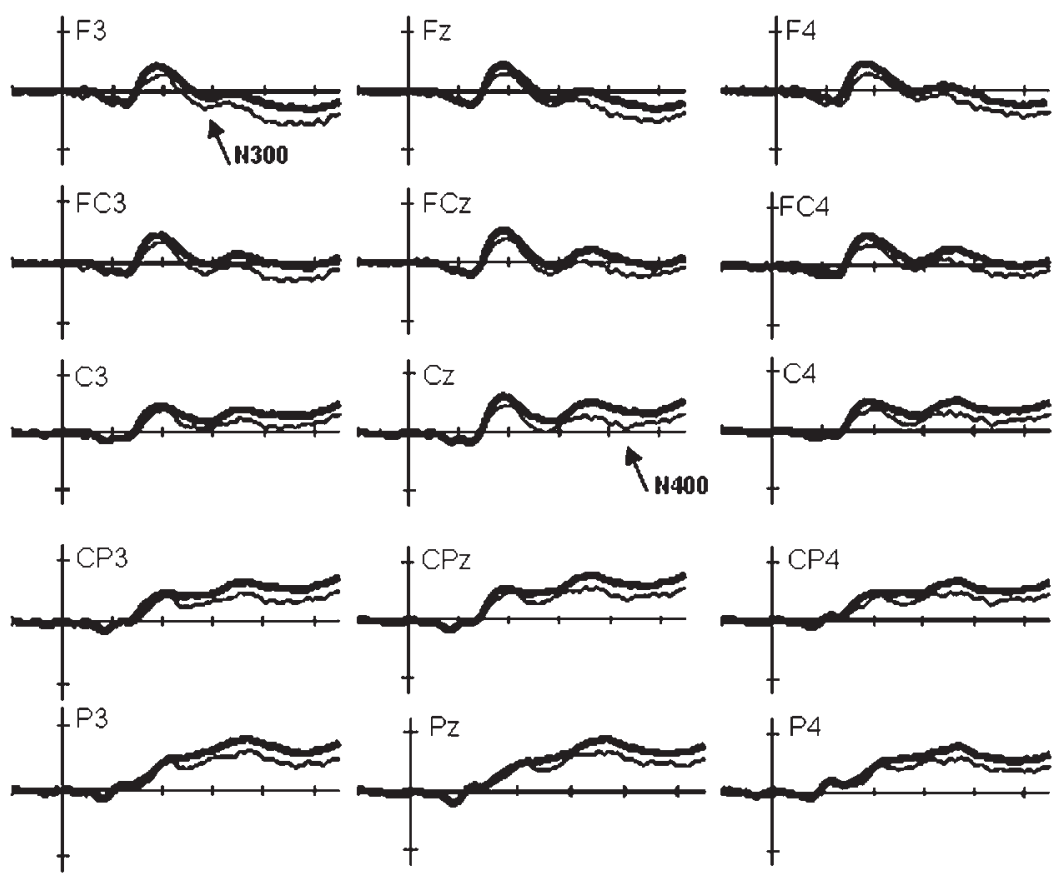

\section{Spatial orienting}
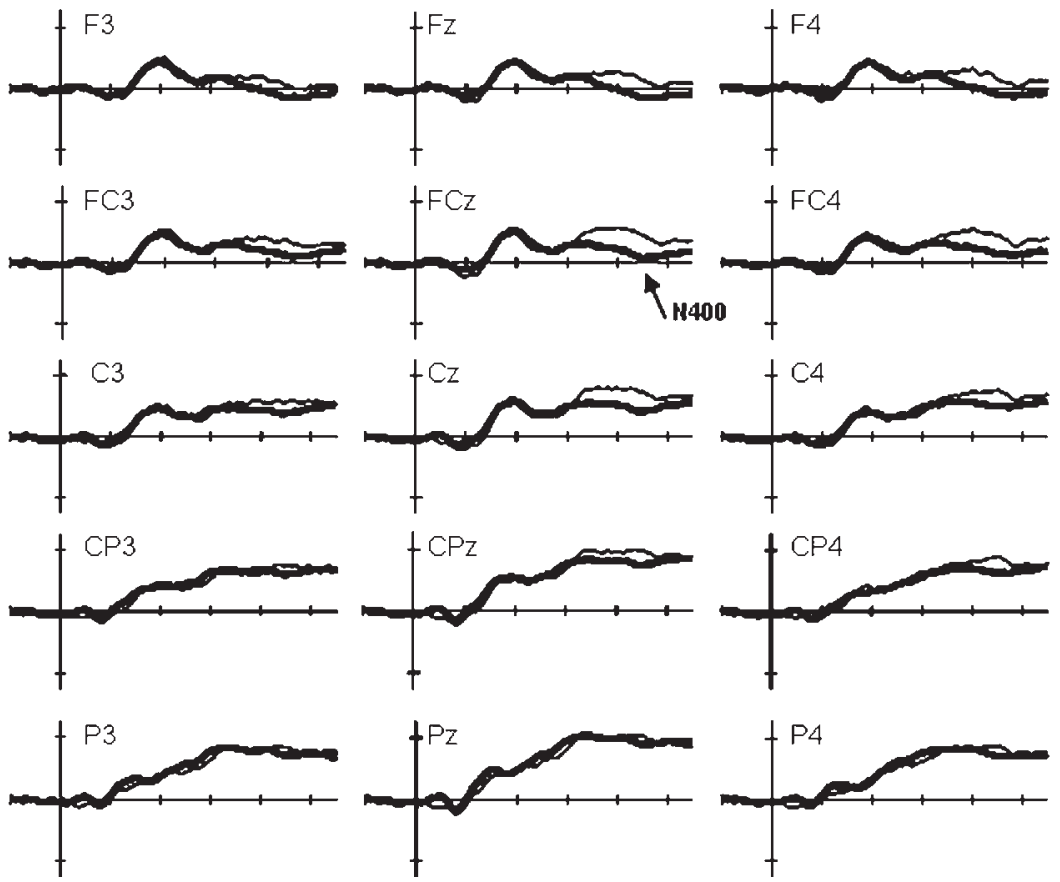
during the N400 interval (350-550 msec) in the semanticorienting and spatial-orienting conditions. The topographical maps that best explained the validity effects during this interval differed significantly between orienting conditions. Segmentation of the grand-averaged subtraction waveforms (validity effect) resulted in a total of five topographical maps. During the period of the N400 potential, the maps in the semantic-orienting versus spatial-orienting conditions were different. The validity effects in the semantic-orienting condition were best described by Map 5, showing a diffuse distribution centered over midline electrodes, ranging from frontal to parietal electrodes. During this time, the waveforms elicited by validly cued targets were less negative. The validity effects in the spatial-orienting condition were best described by Map 3, showing a more focused modulation over frontal to central electrodes. During this time, the

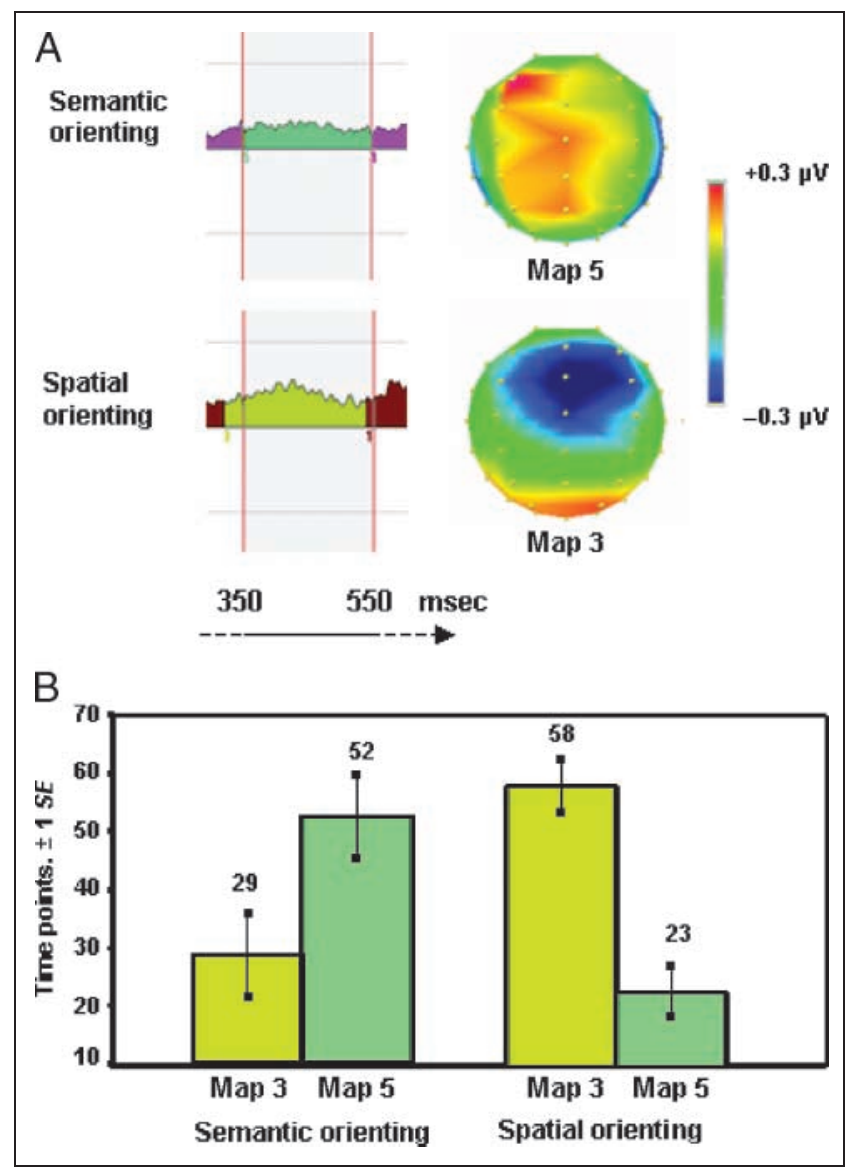

Figure 5. The top panel shows the topographical segmentation of the attention-orienting effects (i.e., valid-minus-invalid subtraction waveforms) in the semantic-orienting and spatial-orienting conditions between the N400 analysis period (350-550 msec), and the associated topographical distributions for the attention effects during this time period. (A) During the N400 period (350-550 msec), Map 5 offered the best representation of activity in the semantic-orienting condition, whereas Map 3 offered the best representation of activity in the spatial-orienting condition. (B) The bottom graph shows the results from the ANOVA testing the distribution of the two maps in each attentional orienting condition. polarity of the modulation was the opposite, with waveforms elicited by validly cued targets being more negative. The significance of this differential pattern of distribution was confirmed by an ANOVA performed on values resulting from the segmentation analysis to reveal which map was significantly more present in one orienting condition than in the other. The ANOVA tested the factors of map (Map 3 and Map 5) and task (semantic-orienting and spatial-orienting), and revealed a significant interaction between the two factors $[F(1,26)=12.56, p=.002]$. This result confirmed statistically that Map 5 best described the neural activity supporting the modulatory effects of semantic orienting, whereas Map 3 represented the best description of neural activity supporting spatial orienting.

\section{Exploratory Analyses}

Exploratory analyses comparing valid cueing conditions in the semantic-orienting and spatial-orienting tasks revealed an early (150-200 msec) modulation by task over central-parietal sites (CPz, CP3, Pz, P3, and PO3). Visual inspection shows a negative-going potential during this time window for targets in the semantic-orienting task, which is diminished or absent in the spatial-orienting task. Exploratory analyses of cue validity within the semantic task revealed an additional early (150-200 msec) modulation over a restricted set of frontal electrodes (F4/Fz/F3, FCz, F8, and FT8). Visual waveform inspection showed a positive peak located at these sites, whose amplitude was larger for validly cued targets than for invalidly cued targets. No additional effects of cue validity were observed for spatial orienting.

\section{DISCUSSION}

The broad aim of this experiment was to test whether attentional modulatory mechanisms can influence highlevel, associative stages of information processing in the absence of direct perceptual or motor effects. By manipulating expectations about semantic categories of words, we revealed significant benefits in behavioral performance that were accompanied by modulation of language-related ERP components that have been linked to semantic analysis and integration. The nature of these top-down attentional influences differed substantially from those conferred by expectations about the spatial location of words, which instead started with enhancement of components related to the perceptual analysis of word stimuli.

\section{Effects of Semantic and Spatial Orienting on Behavioral Performance}

The present study demonstrated that semantic and spatial attentional orienting brought about similar behavioral benefits. Significant cue-validity effects on performance 
accuracy and RTs were observed in both orienting tasks. Participants detected word targets more quickly and with higher accuracy when they were preceded by valid semantic- or spatial-orienting cues than when cues were invalid. These results clearly demonstrated the ability to use information about the high-level and associative feature of semantic category to improve behavioral performance (Cristescu et al., 2006; Neely, 1976; Posner \& Snyder, 1975a, 1975b). Results demonstrated that participants used the predictions in the cueing stimuli to build expectations about the semantic category of the upcoming word. The current study confirmed the hypothesis that attentional orienting can use abstract, associative postperceptual information, which is independent of motor functions, in order to improve behavioral performance.

\section{Effects of Semantic and Spatial Orienting on Brain Activity}

Because of the left hemisphere dominance for word processing, processing of word stimuli presented in the left VF crosses the corpus callosum to access lateralized language-related brain areas. To avoid mixing stimuli whose processing was dependent versus independent of callosal crossing, only ERPs elicited by stimuli presented in the right $\mathrm{VF}$, and therefore reaching the left hemisphere directly, were analyzed. Behavioral analysis showed that accuracy and RTs to detect words presented in the right VF were significantly better, further supporting the use of these words separately for ERP analysis.

The main hypothesis guiding this study was that semantic and spatial orienting would exert distinct modulatory effects on word processing. We hypothesized that the modulatory effects of spatial orienting would start during early visual stages of word processing, but that semantic orienting would affect only later, semantic stages of processing. The temporal resolution of the ERP technique makes it suitable to track how different types of expectations modulate brain activity in real time, and allowed us to identify the levels of word processing at which semantic and spatial orienting modulated information processing.

\section{Spatial Orienting}

The results supported our hypothesis. As predicted, spatial orienting enhanced the processing of word stimuli starting from early visual analysis. The first identifiable visual potential, P1, was significantly larger when participants attended to the spatial location of the target stimulus compared to the P1 elicited by unattended stimuli. This result replicated previous ERP studies of spatial orienting toward simple stimuli (Hillyard \& Anllo-Vento, 1998; Hillyard, Teder-Salejarvi, \& Munte, 1998; Hillyard, Vogel, et al., 1998; Mangun et al., 1998; Mangun et al., 1993; Mangun \& Hillyard, 1987) as well as complex lin- guistic stimuli like words (McCarthy \& Nobre, 1993). In line with previous experiments using bilateral target arrays, no attentional modulation of the subsequent, N1, potential was observed (Luck et al., 1990). The pattern of P1 lateralization differed from previous reports, as the P1 was enhanced bilaterally over the occipital areas and not contralateral to the attended location (Heinze \& Mangun, 1995; Heinze et al., 1994; Heinze, Luck, Mangun, \& Hillyard, 1990; Luck et al., 1990). Various aspects related to the experimental design used in the current study, such as task difficulty and the trial-by-trial cueing paradigm, probably influenced the pattern of P1 modulation (see Lange, Wijers, Mulder, \& Mulder, 1999).

So far, only a limited number of studies have investigated the modulatory effects of spatial attention on the neural processing of words (e.g., Dell'acqua, Pesciarelli, Jolicoeur, Eimer, \& Peressotti, 2007; Zhang \& Zhang, 2006; Bentin, Kutas, \& Hillyard, 1995; McCarthy \& Nobre, 1993). The present finding of P1 modulation confirms the ability of spatial attention to modulate early stages of stimulus processing, even in the case of complex word stimuli presented in their canonical orientation. This strongly suggests that spatial attention can bias the processing of words through similar types of gain-control mechanisms as for other types of visual stimuli (Hillyard \& Anllo-Vento, 1998; Hillyard, Vogel, et al., 1998; Hillyard \& Mangun, 1987).

After the modulation of early visual potentials, spatial orienting also affected later, language-related potentials, especially during the time period of the N400 potential. Attended targets elicited a more prominent (negative) N400 effect, whereas unattended targets elicited a more attenuated N400. This effect was distributed over frontal and central regions of the scalp, replicating previous reports (McCarthy \& Nobre, 1993). The findings provide further experimental evidence that attention can modulate postperceptual stages of word processing, such as semantic analysis or integration (Miniussi, Marzi, \& Nobre, 2005; Rees, Russell, et al., 1999; Bentin et al., 1995; McCarthy \& Nobre, 1993; Holcomb, 1988). The findings do not, of course, rule out some residual semantic processing of unattended words (Ruz, Wolmetz, Tudela, \& McCandliss, 2005; Ruz, Worden, Tudela, \& McCandliss, 2005; Marcel \& Patterson, 1978). The precise languagerelated processes modulated by spatial attention during the N400 period remain uncertain, as there is yet no definitive consensus regarding the neural basis or functional significance of the N400. The N400 probably reflects activity in a number of brain areas, including medial and lateral temporal cortices and the frontal cortex (Halgren, 2004; Tarkiainen, Helenius, Hansen, Cornelissen, \& Salmelin, 1999; Nobre \& McCarthy, 1994, 1995). Multiple aspects of semantic analysis or integration may take place during this period, and these may be dissociable to some extent. The frontal distribution of the spatial attention effect suggests that only a selective number of neural generators contribute. It is also possible that a late effect of selection 
negativity contributed to the larger negative component elicited by validly cued words (Anllo-Vento \& Hillyard, 1996; Aine \& Harter, 1986).

Altogether, the pattern of neural modulation of word stimuli by spatial attention, starting from early perceptual stages and persisting through later semantic analysis, is consistent with reformulations of early-selection theories of attention (Treisman, 1960, 1964, 1969) or with multilevel-selection theories (Kastner \& Pinsk, 2004; Nobre, 2004).

\section{Semantic Orienting}

As predicted, semantic orienting did not modulate the visual potentials, but affected only later stages of word processing. The main effects of semantic orienting appeared between 260 and 550 msec during the N300 and N400 potentials, which have been associated with semantic processing of words (Franklin et al., 2007; Kutas \& Federmeier, 2000; Deacon, Mehta, Tinsley, \& Nousak, 1995; Nobre \& McCarthy, 1994; Holcomb \& Neville, 1990; Bentin et al., 1985; Kutas \& Hillyard, 1984). Similar but perhaps nonidentical stages of conceptual or semantic analysis or integration have also been identified for pictorial stimuli (e.g., West \& Holcomb, 2002). Targets preceded by invalid semantic cues elicited more prominent N300 and N400 potentials compared to targets preceded by valid semantic cues. Again, the precise generators or functional underpinnings of the effect remain to be determined. However, the different scalp distribution of the semantic-orienting effect compared to the spatial-orienting effect clearly shows that the brain areas modulated by these different types of expectations, and therefore, the specific psychological functions involved, are not the same. Central to the main aim of the experiment was the ability of controlled expectations to modulate neural processing directly at this high level of associative stage of neural processing.

The pattern of N400 modulation in the semanticorienting task was reminiscent of the pattern of modulation occurring as a result of semantic priming (Bentin et al., 1985). Semantic orienting may, like controlled aspects of semantic priming, have invoked the operation of semantic expectations and semantic matching (Franklin et al., 2007; Rossell, Price, \& Nobre, 2003; Neely, Keefe, \& Ross, 1989). The experimental design used arbitrary, nonverbal cueing stimuli, which eliminated any possible contribution of automatic semantic associations between cue and target. Long cue-target intervals were also used to afford controlled semantic expectations (Neely et al., 1989; De Groot, 1984; den Heyer, Briand, \& Dannenbring, 1983; Neely, 1977). These manipulations ensured that the N300 and N400 modulations resulted from voluntary attentional processes based on semantic information. Most likely, the symbolic cues triggered the expectation of a cohort of words from the predicted semantic category (Neely et al., 1989), leading to activation of these and other related concepts. Preactivation of concepts in a given semantic category then resulted in diminished neural activity required to process validly cued incoming word stimuli. Semantic matching functions may also have contributed (Franklin et al., 2007). The realization that a given word belonged to the cued semantic category would have facilitated the decision that the item constituted a real word, facilitating the lexical-decision response.

Overall, the findings from semantic-orienting reinforce those in the spatial-orienting task, showing that word processing is not fully automatic, but instead can be biased by top-down signals related to expectations. However, the findings also showed that the mechanisms by which semantic orienting biased word processing differed from the mechanisms utilized by spatial attention.

\section{Comparison between Semantic and Spatial Orienting}

A major conclusion to emerge from the present study concerns the distinct patterns of attentional modulation induced by semantic versus spatial orienting. The ERP analysis revealed different and nonoverlapping patterns of modulation on word processing specific to each attention orienting condition. Different types of expectations can modulate different stages of processing. Whereas spatial expectations can afford the biasing of activity within visual neurons that have retinotopic receptive fields, expectations about semantic categories alone have no way of modulating spatial or featurerelated processing in visual areas. Interestingly, even when modulation affected information processing during the same time period, for example, in the N400 time window, this occurred via different mechanisms.

The polarity of the N400 orienting effect was different in the semantic-orienting task compared to the spatialorienting task. Valid semantic cueing attenuated the N400, whereas valid spatial cueing enhanced it. The topographical analysis of the attentional effects also showed a differential pattern of neural activity in the semantic- and spatial-orienting conditions. The effect in the semanticorienting task had a widespread midline-central and midline-posterior distribution, which is consistent with previous descriptions of N400 topography (Halgren, Baudena, Heit, Clarke, \& Marinkovic, 1994; Curran, Tucker, Kutas, \& Posner, 1993; Kutas, Van Petten, \& Besson, 1988; Kutas \& Hillyard, 1982). The N400 effects observed in the spatial-orienting condition had a frontalcentral distribution, which was similar to that observed in the spatial orienting experiment by McCarthy and Nobre (1993). This result suggests that different sets of brain areas, and presumably different psychological functions, were modulated by semantic versus spatial orienting within the N400 time period.

In addition to the specific effects of attentional orienting within each condition, tonic attentional modulations 
relating to the emphasis of each task on semantic versus spatial attributes were also observed. Overall, the language-related potentials, especially the N400, were larger in the group performing the semantic-orienting task compared to the group performing the spatialorienting task. This suggests that when semantic attributes of words are salient or task relevant, potentials reflecting this stage of processing are enhanced (Miniussi et al., 2005; Holcomb, 1988). The finding is compatible with increased overall levels of activation in brain areas coding specific stimulus attributes that are attended in hemodynamic imaging tasks (Gitelman, Nobre, Sonty, Parrish, \& Mesulam, 2005; Corbetta, Miezin, Dobmeyer, Shulman, \& Petersen, 1990, 1991).

In addition, an exploratory analysis revealed modulation of an early ERP component (150-200 msec) when semantic categories were made salient by task content, hinting at the existence of much earlier stages of brain activity sensitive to lexical or semantic dimensions of word stimuli (see also Rossell et al., 2003). Future experiments should continue to probe the existence of early stages of lexical or semantic processing, in line with our ability to recognize words very rapidly.

Overall, the findings suggest that there are multiple and flexible attentional orienting mechanisms depending on task context and on the specific expectations engaged within a task. When relevant or expected stimuli are distinguished by simple perceptual attributes, top-down modulation can bias information processing from these early stages. In the case of spatial attention to visual words, the spatial receptive-field properties can be used, resulting in enhanced retinotopic analysis of expected relative to unexpected stimuli. These early perceptual effects can cascade through the successive stages of information processing, resulting in sustained processing benefits through high-level lexical or semantic stages of processing. This study shows that in the absence of simple features, top-down attentional mechanisms can bias high-level, associative features directly to optimize behavioral performance. Emphasis on semantic attributes led to a relative enhancement of potentials related to semantic analysis, suggesting a tonic enhancement of these stages of processing (see also Miniussi et al., 2005). In contrast, specific expectations about a given semantic category seem to lead to preactivation of semantic representations in the cued category. Rather than operating through a constant set of mechanisms, attentional orienting therefore is seen to operate using an extensive repertoire, through which processing resources are aligned according to the task content and changing expectations.

Reprint requests should be sent to Anna Christina Nobre, Department of Experimental Psychology, University of Oxford, South Parks Road, Oxford, OX1 3UD, UK, or via e-mail: kia.nobre@ psy.ox.ac.uk.

\section{REFERENCES}

Aine, C. J., \& Harter, M. R. (1986). Visual event-related potentials to colored patterns and color names: Attention to features and dimension. Electroencephalography and Clinical Neurophysiology, 64, 228-245.

Anllo-Vento, L., \& Hillyard, S. A. (1996). Selective attention to the color and direction of moving stimuli: Electrophysiological correlates of hierarchical feature selection. Perception \& Psychophysics, 58, 191-206.

Anllo-Vento, L., Luck, S. J., \& Hillyard, S. A. (1998). Spatio-temporal dynamics of attention to color: Evidence from human electrophysiology. Human Brain Mapping, 6, 216-238.

Bentin, S., Kutas, M., \& Hillyard, S. A. (1995). Semantic processing and memory for attended and unattended words in dichotic listening: Behavioral and electrophysiological evidence. Journal of Experimental Psychology: Human Perception and Performance, 21, 54-67.

Bentin, S., McCarthy, G., \& Hillyard, S. A. (1985). Event-related potentials, lexical decision and semantic priming. Electroencephalography and Clinical Neurophysiology, 60, 343-355.

Bookheimer, S. (2002). Functional MRI of language: New approaches to understanding the cortical organization of semantic processing. Annual Reviews in Neuroscience, 25, 151-188.

Brandeis, D., Naylor, H., Halliday, R., Callaway, E., \& Yano, L. (1992). Scopolamine effects on visual information processing, attention, and event-related potential map latencies. Psychophysiology, 29, 315-336.

Coltheart, M. (1981). The MRC psycholinguistics database. Quarterly Journal of Experimental Psychology, 33, 497-505.

Corbetta, M., Miezin, F. M., Dobmeyer, S., Shulman, G. L., \& Petersen, S. E. (1990). Attentional modulation of neural processing of shape, color, and velocity in humans. Science, 248, 1556-1559.

Corbetta, M., Miezin, F. M., Dobmeyer, S., Shulman, G. L., \& Petersen, S. (1991). Selective and divided attention during visual discriminations of shape, color, and speed: Functional anatomy by positron emission tomography. Journal of Neuroscience, 11, 2383-2402.

Cristescu, T. C., Devlin, J. T., \& Nobre, A. C. (2006). Orienting attention to semantic categories. Neuroimage, 33, 1178-1187.

Curran, T., Tucker, D. M., Kutas, M., \& Posner, M. I. (1993). Topography of the N400: Brain electrical activity reflecting semantic expectancy. Electroencephalography and Clinical Neurophysiology, 88, 188-209.

De Groot, A. M. B. (1984). Primed lexical decision: Combined effects of the proportion of related prime-target pairs and the stimulus-onset asynchrony of prime and target. The Quarterly Journal of Experimental Psychology, 36A, 253-280.

Deacon, D., Mehta, A., Tinsley, C., \& Nousak, J. M. (1995). Variation in the latencies and amplitudes of N400 and NA as a function of semantic priming. Psychophysiology, 32, 560-570.

Dell'acqua, R., Pesciarelli, F., Jolicoeur, P., Eimer, M., \& Peressotti, F. (2007). The interdependence of spatial attention and lexical access as revealed by early asymmetries in occipito-parietal ERP activity. Psychophysiology, 44, 436-443.

Delorme, A., \& Makeig, S. (2004). EEGLAB: An open source toolbox for analysis of single-trial EEG dynamics including independent component analysis. Journal of Neuroscience Methods, 134, 9-21.

den Heyer, K., Briand, K., \& Dannenbring, G. L. (1983). Strategic factors in a lexical-decision task: Evidence for 
automatic and attention-driven processes. Memory $\varepsilon$ Cognition, 11, 374-381.

Doherty, J. R., Rao, A., Mesulam, M. M., \& Nobre, A. C. (2005). Synergistic effect of combined temporal and spatial expectations on visual attention. Journal of Neuroscience, 25, 8259-8866.

Eason, R. G. (1981). Visual evoked potential correlates of early neural filtering during selective attention. Bulletin of the Psychonomic Society, 18, 203-206.

Eason, R. G., Harter, M. R., \& White, C. T. (1969). Effects of attention and arousal on visually evoked cortical potentials. Physiology and Behavior, 4, 283-289.

Franklin, M. S., Dien, J., Neely, J. H., Huber, E., \& Waterson, L. D. (2007). Semantic priming modulates the N400, N300, and N400RP. Clinical Neurophysiology, 118, 1053-1068.

Gitelman, D. R., Nobre, A. C., Sonty, S., Parrish, T., Mesulam, M.-M. (2005). Language network specializations: An analysis with parallel task designs and functional magnetic resonance imaging. Neuroimage, 26, 975-985.

Griffin, I. C., Miniussi, C., \& Nobre, A. C. (2002). Multiple mechanisms of selective attention: Differential modulation of stimulus processing by attention to space or time. Neuropsychologia, 40, 2325-2340.

Halgren, E. (2004). How can intracranial recordings assist MEG source localization? Neurology and Clinical Neurophysiology, 2004, 86.

Halgren, E., Baudena, P., Heit, G., Clarke, M., \& Marinkovic, K. (1994). Spatio-temporal stages in face and word processing: 2. Depth-recorded potentials in the human frontal and Rolandic cortices. Journal of Physiology Paris, 88, 51-80.

Heinze, H. J., Luck, S. J., Mangun, G. R., \& Hillyard, S. A. (1990). Visual event-related potentials index focused attention within bilateral stimulus arrays. I. Evidence for early selection. Electroencephalography and Clinical Neurophysiology, 75, 511-527.

Heinze, H. J., \& Mangun, G. R. (1995). Electrophysiological signs of sustained and transient attention to spatial locations. Neuropsychologia, 33, 889-908.

Heinze, H. J., Mangun, G. R., Burchert, W., Hinrichs, H., Scholz, M., Münte, T. F., et al. (1994). Combined spatial and temporal imaging of brain activity during visual selective attention in humans. Nature, 372, 543-546.

Hillyard, S. A., \& Anllo-Vento, L. (1998). Event-related brain potentials in the study of visual selective attention. Proceedings of the National Academy of Sciences, U.S.A., 95, 781-787.

Hillyard, S. A., Hink, R. F., Schwent, V. L., \& Picton, T. W. (1973). Electrical signs of selective attention in the human brain. Science, 182, 177-180.

Hillyard, S. A., \& Mangun, G. R. (1987). Sensory gating as a physiological mechanism for visual selective attention. Electroencephalography and Clinical Neurophysiology Supplement, 40, 61-67.

Hillyard, S. A., Teder-Salejarvi, W. A., \& Munte, T. F. (1998). Temporal dynamics of early perceptual processing. Current Opinion in Neurobiology, 8, 202-210.

Hillyard, S. A., Vogel, E. K., \& Luck, S. J. (1998). Sensory gain control (amplification) as a mechanism of selective attention: Electrophysiological and neuroimaging evidence. Philosophical Transactions of the Royal Society London, Series B, Biological Sciences, 353, 1257-1270.

Holcomb, P. J. (1988). Automatic and attentional processing: An event-related brain potential analysis of semantic priming. Brain and Language, 35, 66-85.

Holcomb, P. J., \& Neville, H. (1990). Auditory and visual semantic priming in lexical decision: A comparison using event-related brain potentials. Language and Cognitive Processes, 5, 281-312.
Jennings, J. R., \& Wood, C. C. (1976). Letter: The epsilon-adjustment procedure for repeated-measures analyzes of variance. Psychophysiology, 13, 277-278.

Kastner, S., \& Pinsk, M. A. (2004). Visual attention as a multilevel selection process. Cognitive, Affective $\varepsilon$ Behavioural Neuroscience, 4, 483-500.

Khateb, A., Annoni, J. M., Landis, T., Pegna, A. J., Custodi, M. C., Fonteneau, E., et al. (1999). Spatio-temporal analysis of electric brain activity during semantic and phonological word processing. International Journal of Psychophysiology, 32, 215-231.

Kutas, M., \& Federmeier, K. D. (2000). Electrophysiology reveals semantic memory use in language comprehension. Trends in Cognitive Sciences, 4, 463-470.

Kutas, M., \& Hillyard, S. A. (1980). Reading senseless sentences: Brain potentials reflect semantic incongruity. Science, 207, 203-205.

Kutas, M., \& Hillyard, S. A. (1982). The lateral distribution of event-related potentials during sentence processing. Neuropsychologia, 20, 579-590.

Kutas, M., \& Hillyard, S. A. (1984). Brain potentials during reading reflect word expectancy and semantic association. Nature, 307, 161-163.

Kutas, M., Van Petten, C., \& Besson, M. (1988). Event-related potential asymmetries during the reading of sentences. Electroencephalography and Clinical Neurophysiology, 69, 218-233.

Lange, J. J., Wijers, A. A., Mulder, L. J. M., \& Mulder, G. (1999). ERP effects of spatial attention and display search with unilateral and bilateral stimulus displays. Biological Psychology, 50, 203-233.

Lehman, D. (1987). Principle of spatial analysis. In A. S. Gevins (Ed.), Handbook of electroencephalography and clinical neurophysiology. Methods of analysis of brain electrical and magnetic signals (Vol. 1, pp. 309-354). Amsterdam: Elsevier.

Luck, S. J., \& Ford, M. A. (1998). On the role of selective attention in visual perception. Proceedings of the National Academy of Sciences, U.S.A., 95, 825-830.

Luck, S. J., Heinze, H. J., Mangun, G. R., \& Hillyard, S. A. (1990). Visual event-related potentials index focused attention within bilateral stimulus arrays: II. Functional dissociation of P1 and N1 components. Electroencephalography and Clinical Neurophysiology, 75, 528-542.

Mangun, G. R., Buonocore, M. H., Girelli, M., \& Jha, A. P. (1998). ERP and fMRI measures of visual spatial selective attention. Human Brain Mapping, 6, 383-389.

Mangun, G. R., \& Hillyard, S. A. (1987). The spatial allocation of visual attention as indexed by event-related brain potentials. Human Factors, 29, 195-211.

Mangun, G. R., Hillyard, S. A., \& Luck, S. J. (1993). Electrocortical substrates of visual selective attention. In D. E. Meyer \& S. Kornblum (Eds.), Attention and performance XIV (pp. 219-243). Cambridge: MIT Press.

Marcel, A. J., \& Patterson, C. (1978). Word recognition and production: Reciprocity in clinical and normal studies. In J. Requin (Ed.), Attention and performance VII (pp. 209-226). Hillsdale, NJ: Erlbaum.

McCarthy, G., \& Nobre, A. (1993). Modulation of semantic processing by spatial selective attention. Electroencephalography and Clinical Neurophysiology, 88, 210-219.

Michel, C. M., Henggeler, B., \& Lehmann, D. (1992). 42-Channel potential map series to visual contrast and stereo stimuli: Perceptual and cognitive event-related segments. International Journal of Psychophysiology, $12,133-145$. 
Miniussi, C., Marzi, C. A., \& Nobre, A. C. (2005). Modulation of brain activity by selective task sets observed using event-related potentials. Neuropsychologia, 43, 1514-1528.

Miniussi, C., Wilding, E. L., Coull, J. T., \& Nobre, A. C. (1999). Orienting attention in time. Modulation of brain potentials. Brain, 122, 1507-1518.

Molholm, S., Ritter, W., Murray, M. M., Javitt, D. C., Schroeder, C. E., \& Foxe, J. J. (2002). Multisensory auditory-visual interactions during early sensory processing in humans: A high-density electrical mapping study. Brain Research, Cognitive Brain Research, 14, 115-128.

Moores, E., Laiti, L., \& Chelazzi, L. (2003). Associative knowledge controls deployment of visual selective attention. Nature Neuroscience, 6, 182-189.

Murray, M. M., Wylie, G. R., Higgins, B. A., Javitt, D. C., Schroeder, C. E., \& Foxe, J. J. (2002). The spatiotemporal dynamics of illusory contour processing: Combined high-density electrical mapping, source analysis, and functional magnetic resonance imaging. Journal of Neuroscience, 22, 5055-5073.

Neely, J. (1976). Semantic priming and retrieval from lexical memory: Evidence for facilitatory and inhibitory processes. Memory \& Cognition, 4, 648-654.

Neely, J. (1977). Semantic priming and retrieval from lexical memory: Roles of inhibitionless spreading activation and limited-capacity attention. Journal of Experimental Psychology: General, 106, 226-254.

Neely, J. H., Keefe, D. E., \& Ross, K. (1989). Semantic priming in the lexical decision task: Roles of prospective prime-generated expectancies and retrospective semantic matching. Journal of Experimental Psychology: Learning, Memory, and Cognition, 15, 1003-1019.

Nobre, A. C. (2004). Probing the flexibility of attentional orienting in the human brain. In M. I. Posner (Ed.), Cognitive neuroscience of attention (pp. 157-180). New York: Guilford Press.

Nobre, A. C., \& McCarthy, G. (1994). Language-related ERPs: Scalp distributions and modulation by word type and semantic priming. Journal of Cognitive Neuroscience, 6, 233-255.

Nobre, A. C., \& McCarthy, G. (1995). Language-related field potentials in the anterior-medial temporal lobe: II. Effects of word type and semantic priming. Journal of Neuroscience, 15, 1090-1098.

Oldfield, R. C. (1971). The assessment and analysis of handedness: The Edinburgh inventory. Neuropsychologia, 9, 97-113.

Ortigue, S., Michel, C. M., Murray, M. M., Mohr, C., Carbonnel, S., \& Landis, T. (2004). Electrical neuroimaging reveals early generator modulation to emotional words. Neuroimage, 21, 1242-1251.

Pascual-Marqui, R. D., Michel, C. M., \& Lehmann, D. (1995). Segmentation of brain electrical activity into microstates: Model estimation and validation. IEEE Transactions on Bio-Medical Engineering, 42, 658-665.

Posner, M. I. (1980). Orienting of attention. Quarterly Journal of Experimental Psychology, 32, 3-25.
Posner, M. I., \& Snyder, C. R. R. (1975a). Attention and cognitive control. In R. L. Solso (Ed.), Information processing and cognition: The Loyola Symposium (pp. 54-85). Hillsdale, NJ: Erlbaum.

Posner, M. I., \& Snyder, C. R. R. (1975b). Facilitation and inhibition in the processing of signals. In P. M. A. Rabbitt \& S. Dornic (Eds.), Attention and performance $V$ (pp. 669-682). New York: Academic Press.

Posner, M. I., Snyder, C. R. R., \& Davidson, B. J. (1980). Attention and the detection of signals. Journal of Experimental Psychology: General, 109, 160-174.

Rees, G., Russell, C., et al. (1999). Inattentional blindness versus inattentional amnesia for fixated but ignored words. Science, 286, 2504-2507.

Rossell, S. L., Price, C. J., \& Nobre, A. C. (2003). The anatomy and time course of semantic priming investigated by fMRI and ERPs. Neuropsychologia, 41, 550-564.

Ruz, M., Wolmetz, M. E., Tudela, P., \& McCandliss, B. D. (2005). Two brain pathways for attended and ignored words. Neuroimage, 27, 852-861.

Ruz, M., Worden, M. S., Tudela, P., \& McCandliss, B. D. (2005). Inattentional amnesia to words in a high attentional load task. Journal of Cognitive Neuroscience, 17, 768-776.

Tarkiainen, A., Helenius, P., Hansen, P. C., Cornelissen, P. L., \& Salmelin, R. (1999). Dynamics of letter string perception in the human occipitotemporal cortex. Brain, 122, 2119-2132.

Thompson-Schill, S. L., D'Esposito, M., \& Kan, I. P. (1999). Effects of repetition and competition on activity in left prefrontal cortex during word generation. Neuron, 23, 513-522.

Treisman, A. M. (1960). Contextual cues in selective listening. Quarterly Journal of Experimental Psychology, 12, 242-248.

Treisman, A. M. (1964). Verbal cues, language and meaning in selective attention. American Journal of Physiology, 77, 206-219.

Treisman, A. M. (1969). Strategies and models of selective attention. Psychological Review, 23, 157-167.

Valdes-Sosa, M., Bobes, M. A., Rodriguez, V., \& Pinilla, T. (1998). Switching attention without shifting the spotlight object-based attentional modulation of brain potentials. Journal of Cognitive Neuroscience, 10, 137-151.

Valdes-Sosa, M., Cobo, A., \& Pinilla, T. (1998). Transparent motion and object-based attention. Cognition, 66, B13-B23.

Wagner, A. D., Pare-Blagoev, E. J., Clark, J., \& Poldrack, R. A. (2001). Recovering meaning: Left prefrontal cortex guides controlled semantic retrieval. Neuron, 31, 329-338.

West, W. C., \& Holcomb, P. J. (2002). Event-related potentials during discourse-level semantic integration of complex pictures. Brain Research, Cognitive Brain Research, 13, 363-375.

Yantis, S., \& Serences, J. T. (2003). Cortical mechanisms of space-based and object-based attentional control. Current Opinion in Neurobiology, 13, 187-193.

Zhang, M., \& Zhang, Y. (2006). Semantic processing is affected in inhibition of return: Evidence from an event-related potentials study. NeuroReport, 18, 267-271. 